\title{
Pohjoismainen eläinmalli maito-ominaisuuksien arvostelemiseksi
}

\author{
Ismo Strandén, Martin Lidauer ja Esa Mäntysaari \\ MTT Kotieläintuotannon tutkimus, 31600 Jokioinen, etunimi.sukunimi@mtt.fi
}

\section{Johdanto}

Pohjoismaiset keinosiemennysjärjestöt ovat sopineet yhteisestä keinosiemennyssonnien testauksesta ja käytöstä. Hyvän jalostusohjelman perustana ovat luotettavat jalostusarvot. Ulkomailta tuodun jalostusmateriaalin (siemen tai alkiot) ongelmana on vähäinen tai olematon tieto tuotanto- ja arvostelutuloksista alkuperämaassa. Esimerkiksi tiedetään vain sonnin Suomessa tuottavien tyttärien tuotantotiedot. Käytännössä Interbull järjestön tuottamaa kansainvälistä sonnien jalostusarvostelutietoa voidaan käyttää jossain määrin helpottamaan tätä ongelmaa. Tällöin kuitenkaan ei voida huomioida tuontisonnien välisiä sukulaisuuksia ja ulkomaisen alkionsiirto-ohjelman tuottamat alkiot eivät saa riittävää sukulaisten tuomaa arvosteluvarmuutta. Yhteispohjoismainen jalostusarvostelu on tarpeen luotettavan jalostusvalinnan turvaamiseksi. Yhteispohjoismaisessa arvostelussa voidaan täydellisesti huomioida kaikki yksilön sukulaiset muissa pohjoismaassa.

Yli maiden tehtävässä arvostelussa tilastollisesta mallista tulee usein monimutkainen, koska kunkin maan populaatiolla on historiansa ja populaatiorakenteensa, jotka on huomioitu kansallisissa arvosteluissa ja on huomioitava myös ylikansallisessa arvostelumallissa. Toisaalta maiden eri populaatioissa on usein eri rotujen sekoituksia, joten mallissa on huomioitava rotujen risteytysvaikutukset. Lisäksi eri tuotantoympäristöjen erilainen vaikutus ominaisuuksissa havaittavaan vaihteluun vaatii huomioimaan varianssin heterogeenisuuden eri karjojen ja maiden välillä. Tämä on erittäin tärkeätä eläinjalostuksen kannalta, koska jalostuksessa valitaan parhaita yksilöitä. Heterogeenisen varianssin korjauksella eri maiden huippuyksilöiden jalostusarvot saatetaan samalle hajontaskaalalle.

Pohjoismainen tuotanto-ominaisuuksien arvostelumalli on lähtenyt siitä että sen tulee olla kehittyneempi kuin kansalliset jalostusarvostelumallit ja tarjota luotettavat jalostusarvot käytäntöön. Tämä artikkeli kuvaa kyseisen jalostusarvostelun ayrshire-rodulle, joskin vastaava arvostelu on työn alla myös musta-valkoiselle rodulle.

\section{Aineisto ja menetelmät}

Mallissa on lähes 700 tekijää, joten tässä artikkelissa kuvataan mallissa huomioidut tekijät vain yleisesti. Pohjoismaisen jalostusarvostelua kehitettäessä on pitäydytty seuraavissa periaatteissa:

- Kukin maa vastaa omasta mallistaan

- Pohjoismaisessa mallissa kunkin maan mallin tulee olla vähintään yhtä hyvä kuin tällä hetkellä käytetyssä kansallisessa jalostusarvostelussa

- Jalostusarvostelujen maavertailu ei saa olla ristiriidassa nykyisten Interbull-arvostelujen kanssa

- Kukin eläin saa vain yhden jalostusarvon eli geneettinen korrelaatio maiden välillä on yksi

Näiden periaatteiden seurauksena jalostusarvostelumalliin jäi jonkin verran maakohtaisia eroja, vaikka alkuperäismalleja pystyttiinkin yhtenäistämään. Tuotanto-ominaisuuksien arvostelussa on samanaikaisesti mukana maito-, rasva- ja valkuaiskilot ensimmäiseltä, toiselta sekä kolmannelta lypsykaudelta, ja nämä ovat eri ominaisuuksia. Suomen mallissa kaikki lypsykaudet kolmannen jälkeen määritellään toistuvina ilmentyminä kolmannen laktaation jalostusarvosta. Kukin maa on tilastollisessa mallissa omana ominaisuutenaan. Tällä hetkellä arvosteluissa on kolme maata: Ruotsi, Suomi ja Tanska. Yhteensä mallissa on 27 ominaisuutta.

Suomen lypsykarja-arvostelu on perustunut vuodesta 2000 koelypsymalliin (Lidauer \& Mäntysaari, 2000 ja 2002). Ruotsissa on 305 päivän tuotoksiin perustuva eläinmalli. Tanskassa haluttiin käyttää sekä 305 päivän tuotoksia että koelypsymittauksia, koska koelypsymittauksia ei ole tallessa ennen vuotta 1990. Mallista tuli siis satunnaisregressiomalli, jossa voidaan käyttää sekä 305 päivän tuotoksia että koelypsymittauksia. Lisäksi huomioidaan eri tuotantoympäristöistä johtuva heterogeeninen varianssi (Meuwissen ym. 1996).

Taulukossa 1 on eri maiden malleissa olevat ympäristötekijät. Eri maiden mallien tekijöissä on samankaltaisuuksia. Suurimmat erot johtuvat aineistoista. Esimerkiksi, Tanskan mallissa on tilakuukausi mutta Ruotsin mallissa on tilavuosi, koska Tanskasta on koelypsymittauksia ja Ruotsista 305 päivän tuotoksia. Suomen mallissa on tilavuosi ja satunnainen tilakuukausi, koska pienen tilakoon takia 
koelypsymittauksia on liian vähän kiinteän tilakuukausitekijän käyttöön. Kiinteät lypsykäyrät kuvataan toisen asteen polynomilla, jota on täydennetty kahdella lypsykauden alkua tarkentavalla eksponentiaalitekijällä.

Taulukko 1. Ympäristötekijät eri maiden malleissa.

\begin{tabular}{|c|c|c|}
\hline Suomi & Tanska & Ruotsi \\
\hline tilavuosi & tilakuukausi & tilavuosi \\
\hline poikimaikä $* 5$ vuotta & poikimaikä & poikimaikä \\
\hline tuotantovuosi * kuukausi & poikimavuosi $*$ vuodenaika & poikimavuosi*kuukausi \\
\hline tiineyden vaihe & tiineyden vaihe & tyhjäkausi \\
\hline edeltävä tyhjäkauden pituus & edeltävä poikimaväli & $\begin{array}{l}\text { tyhjäkausi (regressio) } \\
\text { edeltävä poikimaväli } * 5 \text { vuotta }\end{array}$ \\
\hline $\begin{array}{l}\text { FLC poikimavuosi } * \text { vuodenaika } \\
\text { pitkämaitoisuus tila } * 5 \text { vuotta } \\
\text { tilakuukausi (satunnainen) }\end{array}$ & $\begin{array}{l}\text { FLC ikä * kuukausi } * 5 \text { vuotta } \\
\text { pitkämaitoisuus tila*5 vuotta }\end{array}$ & \\
\hline heterozygotia (regressio) & heterozygotia (regressio) & heterozygotia (regressio) \\
\hline
\end{tabular}

FLC= kiinteä lypsykäyrä

Taulukossa 2 on eri maiden malleissa olevat eläinkohtaiset satunnaistekijät. Satunnaistekijöitä ovat jo em. tila-koelypsykuukauden lisäksi ns. pysyvä ympäristö (ei-geneettinen eläintekijä) ja jalostusarvo. Koska tuotoshavainnot ovat koelypsymittauksia, nämä tekijät mallinnetaan satunnaisregressioina. Vaikka ruotsalainen aineisto on 305 päivän havaintoja ja niille käytetään monen ominaisuuden mallia, niin käytännössä myös se voidaan toteuttaa ekvivalentisti satunnaisregressiomallina. Tällöin kuitenkin tarvitaan erillinen pysyvä ympäristötekijä. Taulukon 2 mukaan mallissa on kaikkiaan neljä eläinkohtaista eigeneettistä satunnaistekijää. Lisäksi on yksi jalostusarvotekijä, sillä joka eläimelle arvioidaan vain yksi jalostusarvofunktio. Mallissa on siis tilakuukausi huomioiden yhteensä 7 satunnaistekijää. Koska koelypsyhavaintoja mallintavat satunnaistekijät ovat usean parametrin satunnaisregressiofunktioita, arvioitujen varianssikomponenttien määrä on suuri. Varianssikomponenttien parametrejä on yhteensä 545, joista 21 oli Suomen mallin tilakuukaudelle.

Taulukko 2. Maakohtaiset eläinperäiset satunnaistekijät ja niissä huomioidut lypsykaudet.

\begin{tabular}{llccc} 
& Suomi & Tanska & Ruotsi \\
\hline PY: & lypsykaudella & kaikki & $1-3$ & \\
& lypsykausien yli & $3+$ & & \\
305 pv. tuotoksille & & & $1-3$ \\
Eläingeneettinen & kaikki & $1-3$ & $1-3$ \\
\hline PY
\end{tabular}

$\mathrm{PY}=$ pysyvä ympäristötekijä

\section{Tulokset ja tulosten tarkastelu}

Yhteispohjoismainen tuotanto-ominaisuuksien arvostelu lypsykarjalle merkitsee jalostusarvojen samanaikaista arvioimista noin 5,2 miljoonalle eläimelle (Taulukko 3), joista noin 1,9 miljoonalla on tuotostieto. Laskennallisesti tilastollisen mallin ratkaisu voidaan jakaa kahteen osaan: jalostusarvojen arviointi ja heterogeenisen varianssin arviointi. Jalostusarvot ratkaistaan yhtälöryhmästä, jossa on noin 151,8 miljoonaa tuntematonta. Heterogeenisen varianssin arvioimiseksi on ratkaistava noin 2,8 miljoonaa tuntematonta varianssivaikutusta. Käytännössä molemmat vaiheet ratkaistaan iterointimenetelmällä ja näitä kahta toisiinsa liittyvää laskentaosaa vuorotellaan. 
Taulukko 3. Havaintojen ja eläinten määriä yhteispohjoismaisessa jalostusarvostelussa.

\begin{tabular}{|c|c|c|c|c|}
\hline \multirow[b]{3}{*}{ Suomi } & \multirow[b]{2}{*}{ Sukupuussa eläimiä } & \multirow[b]{2}{*}{ Havaintoja elämillä } & \multicolumn{2}{|c|}{ Havaintoja } \\
\hline & & & 305 pv. havaintoja & Koelypsymittauksia \\
\hline & 2655913 & 1393147 & & 33581528 \\
\hline Ruotsi & 1674240 & 1448997 & 2010964 & \\
\hline Tanska & 880108 & 332423 & 527696 & 5528320 \\
\hline Yhteensä & 5210261 & 1920567 & 2538160 & 39109848 \\
\hline
\end{tabular}

Jalostusarvojen ratkaisemiseksi käytettiin Linux-PC klusteria, jossa oli neljä 2 prosessorin työasemaa. Ratkaisemisessa hyödynnettiin neljää prosessoria (Strandén \& Lidauer, 2001). Kussakin PC:ssä oli neljä gigatavua muistia, joten käytettävissä oli yhteensä 16 gigatavua. Jalostusarvojen arviointi ilman heterogeenisten varianssien ratkaisemista vei noin 36 tuntia ja jalostusarvojen ratkaisualgoritmi tarvitsi 948 iteraatiota. Heterogeenisen varianssin samanaikainen arviointi kaksinkertaisti lopullisen ratkaisuajan 70 tuntiin.

Jalostusarvojen korrelaatiot kansallisten ja yhteispohjoismaisten arvostelujen välillä olivat keinosiemennyssonneilla korkeita. Suomalaisiin arvosteluihin korrelaatiot olivat vuosina 1990-1999 syntyneille keinosiemennyssonneille yli $96 \%$ ja useimpina vuosina jopa yli $98 \%$, sillä ovathan yhteispohjoismainen ja kansallinen malli koelypsymalleja. Ruotsalaisilla sonneilla korrelaatiot olivat vielä suurempia, yhtenä vuotena 97\% ja muina yli 98\%. Tämä on hiukan odottamatonta, koska kansallinen malli on toistuvuusmalli mutta yhteispohjoismainen malli on monen ominaisuuden malli. Tanskalaisten arvostelujen välillä on eniten eroa, sillä sonnien koelypsymalli-indeksien korrelaatio aikaisempiin arvosteluihin oli korkeimmillaan 95\% ja viime vuosina vain 90\%. Tanskan kansallinen malli on 305 päivän tuotosmalli kun taas yhteispohjoismaisessa mallissa on koelypsymittauksia, joten alhaisempi korrelaatio oli odotettua. Tosin, vuosien 1995-1998 korrelaatio on hiukan liiankin alhainen, noin 90\%.

Kuvassa 1 ovat maitokilojen geneettiset trendit maittain ensimmäiselle lypsykaudelle. Geneettiset trendit vastaavat hyvin Interbull-arvosteluissa nähtyjä pohjoismaisia trendejä. Muillakin ominaisuuksilla kuvat ovat samankaltaisia, ovathan maito, rasva ja valkuainen positiivistesti hyvin voimakkaasti korreloituneita. Joulukuun testiajojen tulokset kolmannen laktaation jalostusarvoille vaativat vielä tarkistamista. Erityisesti Tanskan trendi kolmannella lypsykaudella ei vastaa ensimmäisen lypsykauden kehitystä.

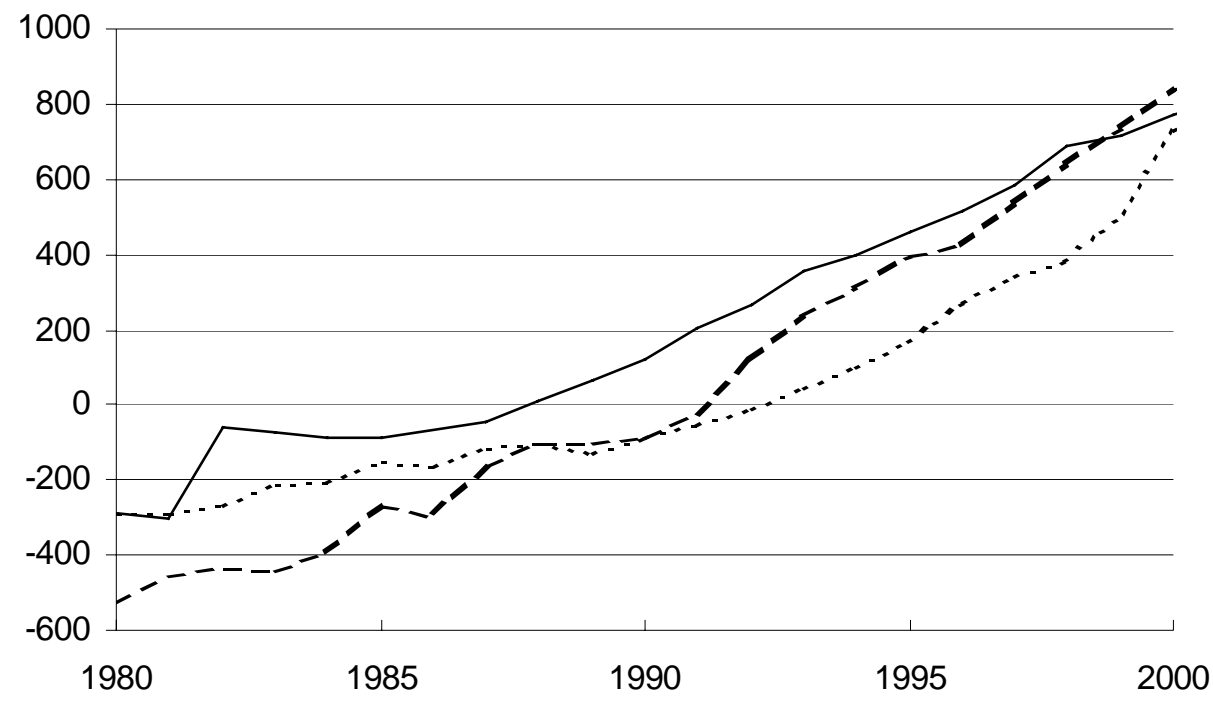

Kuva 1. Maitokilojen geneettinen trendi eri maissa syntymävuoden mukaan. Yhtenäinen viiva= Suomi, Katkoviiva= Ruotsi, Pisteviiva= Tanska.

Kuvassa 2 on esimerkkinä maitokiloja kuvaavan mallin jäännöstermin hajonta ennen ja jälkeen heterogeenisen varianssin korjausta. Heterogeenisen varianssin huomioiminen korjaa ajan myötä kasvavasta hajonnasta johtuvat ongelmat, mutta ei vuoden sisäistä säännönmukaisuutta. Vastaava kuva saadaan 
muillekin ominaisuuksille. Heterogeenisen varianssin korjauksen tärkein vaikutus on heterogeenisen alueerojen korjaus, jolloin esimerkiksi maiden väliset geneettiset hajonnat saadaan oikein.

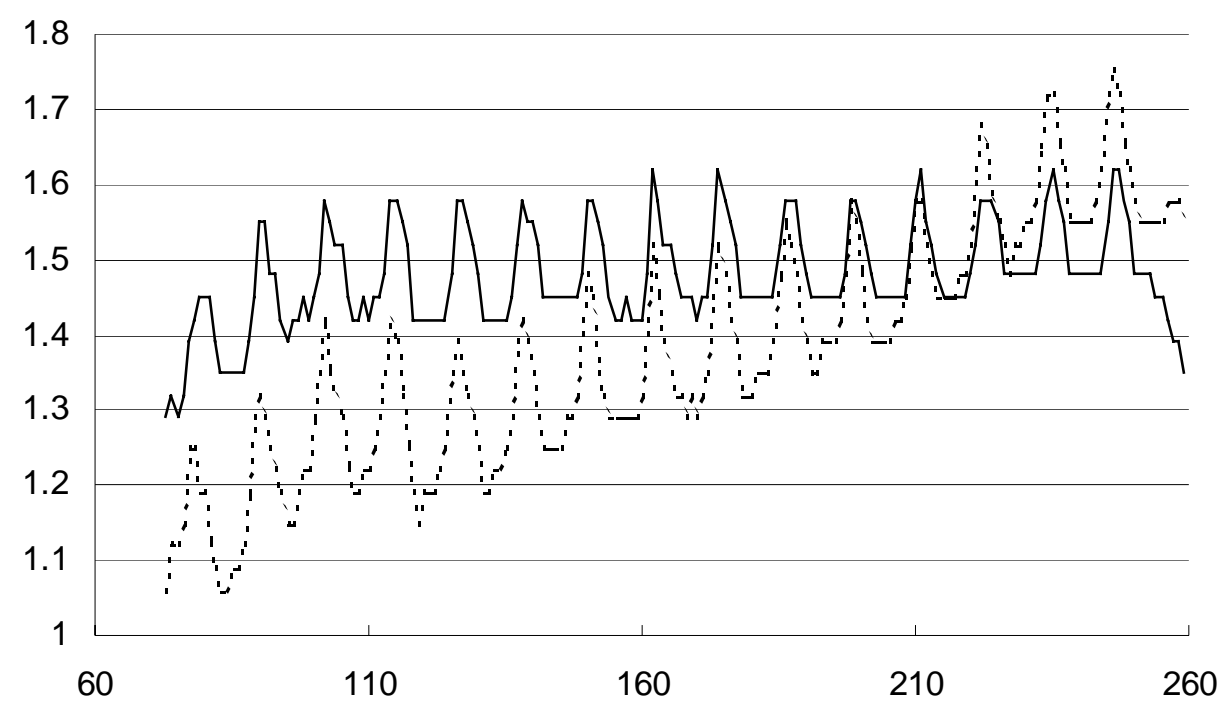

Kuva 2. Jäännöstermin hajonta suomalaisilla lehmillä tuotantovuosina 1988-2003 ennen ja jälkeen heterogeenistä varianssikorjausta (vaaka-akselilla kuukausia vuoden 1988 alusta). Katkoviiva= ennen korjausta, Yhtenäinen viiva= heterogeenisen varianssin korjausmalli.

\section{Johtopäätökset}

Yhteispohjoismainen tuotanto-ominaisuuksien jalostusarvojen arviointi lypsykarjalle vaatii eri maiden mallien kattavaa yhteistä meta-mallia. Tällöin ratkaistavasta ongelmasta tulee monin verroin vaativampi kuin yksittäisten maiden jalostusarvojen arviointi. Mallin on linkitettävä maiden eläimet niin, että maiden väliset geneettiset tasoerot ja hajonnat tulevat oikein. Tämä vaatii sekä mallien yhtenäistämistä että heterogeenisten varianssien huomioimista. Käytännössä tällöin kaikkia malleja on yhtenäistettävä monimutkaisinta mallia kohti. Yhteispohjoismainen arvostelu on kuitenkin mahdollista toteuttaa. Sekä teoreettinen mallinnus että käytännön laskenta ovat mahdollisia. Nyt kehitetty yhteispohjoismainen malli otetaan käyttöön vuoden 2004 aikana ja se mahdollistaa eläinten luotettavan arvostelun pohjoismaiden yli. Tulevaisuuden kehityskohteina ovat mm. ruotsalaisten koelypsyhavaintojen ja norjalaisten lypsykauden tulosten saaminen mukaan yhteisarvosteluun.

\section{Kirjallisuus}

Meuwissen, T.H.E., De Jong, G. \& Engel, B. 1996. Joint estimation of breeding values and heterogeneous variances of large data files. J. Dairy Sci. 79: 310-316.

Lidauer, M. \& Mäntysaari, E. 2002. Karjojensisäisen vaihtelun huomioonottaminen koelypsymallissa. Julkaisussa: Maataloustieteen Päivät 2002 [verkkojulkaisu]. Suomen Maataloustieteellisen Seuran julkaisuja no 18. Toim. Anneli Hopponen. Viitattu 6.10.2004. Julkaistu 1.1.2002. Saatavilla Internetissä:

http://www.agronet.fi/maataloustieteellinenseura/julkaisut/esit/47lidauer.pdf. ISBN 951-9041-46-X.

Lidauer, M., \& Mäntysaari, E. 2000. Lehmien arvostelu koelypsymallilla. Julkaisussa: Maataloustieteen Päivät 2000. Maaseutukeskusten liiton julkaisuja no 952. ISBN 951-808-081-X.

Strandén, I. \& Lidauer, M. 2001. Parallel computing applied to breeding value estimation in dairy cattle. J. Dairy Sci. 84: 276-285. 